\title{
The Possibility of Applying Rumen Research at the Projective Plane PG $(2,17)$
}

\author{
Shaymaa Haleem Ibrahim $^{1} \&$ Nada Yassen Kasm ${ }^{2}$ \\ ${ }^{1}$ Department of Mathematics, College of Computer Sciences and Mathematics, University of Mosul, Mosul, Iraq \\ ${ }^{2}$ Department of Mathematics, College of Education for pure Sciences, University of Mosul, Mosul, Iraq \\ Correspondence: Nada Yassen Kasm , Department of Mathematics, College of Education for pure Sciences, \\ University of Mosul, Mosul, Iraq. E-mail: drnadaqasim1@gmail.com
}

The research is financed by (Sponsoring information)

Received: July 3, 2019

Accepted: July 28, 2019

Online Published: July 29, 2019

doi:10.5539/mas.v13n8p150

URL: https://doi.org/10.5539/mas.v13n8p150

\begin{abstract}
One of the main objectives of this research is to use a new theoretical method to find arcs and Blocking sets. This method includes the deletion of a set of points from some lines under certain conditions explained in a paragraph 2.In this paper we were able to improve the minimum constraint of the $(256,16)-$ arc in the projection plane PG(2,17).Thus, we obtained a new $\{50,2\}$-blocking set for size Less than $3 q$, and according to the theorem (1.3.1),we obtained the linear $[257,3,241]_{17}$ code, theorem( 2.1.1) giving some examples on arcs of the Galois field GF(q);q=17."
\end{abstract}

Keywords: projective plane,(k,r)-arc,2-blocking set ,Linear[n, $k, d]$ code, $\{b, t\}$ - blocking set ,Galois field GF(q)

\section{Introduction}

\subsection{Introduce the Problem}

Numerous studies in algebraic geometry have been found in various sources, including obtaining the optimal size of the projection plane by intersecting the tangent in PG(2,q)(Yahya \&Salim , 2019,pp.312-333), the applications of algebraic geometry, the coding methods, and obtaining the optimal codes( Kasm,\& Hamad,2019,pp.130-139) (Nilsson, Johansson, \& Wagner, 2019, pp. 238-258). Let GF(q) denote the Galois field of q elements and V $(3, q)$ be the vector space of row vectors of length three with entries in $G F(q)$. Let PG(2, q) be the corresponding projective plane( Hirschfeld,1979)."

\subsection{Explore Importance of the Problem}

Definition (1.2.1): A $(\mathrm{k}, \mathrm{r})-$ arc is a set of $\mathrm{k}$ points of a projective plane such that some $\mathrm{r}$, but no $\mathrm{r}+1$ of them, are collinear ( Hirschfeld,1979)."

Definition (1.2.2): A $(\mathrm{b}, \mathrm{t})$ - blocking set $\mathrm{S}$ in $\mathrm{PG}(2, \mathrm{q})$ is a set of $\mathrm{b}$ points such that every line of $\mathrm{PG}(2, \mathrm{q})$ intersects $S$ in at least $n$ points, and there is a line intersecting $S$ in exactly $n$ points. Note that a $(k, r)-\operatorname{arc}$ is the complement of a $\left(\mathrm{q}^{\wedge} 2+\mathrm{q}+1-\mathrm{k}, \mathrm{q}+1-\mathrm{r}\right)$ - blocking set in a projective plane and conversely. (Kasm \& Ibrahim.,2019,pp.)."

Definition(1.2.3):Let $\mathrm{M}$ be a set of points in any plane An i-secant is a line meeting $\mathrm{M}$ in exactly $\mathrm{I}$ points .Define $t_{i}$ as the number of $i$-secants to a set M. ( Hirschfeld,1979)."

Theorem(1.2.4): Let B be a double blocking set in the projection plane PG (2, q): -

1. If $\mathrm{q}<9$, $\mathrm{B}$ has less than $3 \mathrm{q}$ of points.

2. If $q=11,13,17$ or 19 , then $|B| \geq(5 q+7) / 2$ (Kasm \& Ibrahim.,2019,pp.) (Braun, 2018,pp.),(Ball,2018 )

Theorem(1.2.5): To be the $(\mathrm{k}, \mathrm{r})$-arc in the projection plane PG $(2, \mathrm{q})$ the relationship

$$
(\mathrm{q}+1-\mathrm{r}) \mathrm{T}_{\mathrm{r}} \geq \mathrm{q} 2+\mathrm{q}+1-\mathrm{k} . "
$$

Let $\mathrm{V}(\mathrm{n}, \mathrm{q})$ denote the vector space of all ordered $n$-tuples over GF(q). A linear code C over GF(q) of length $n$ and dimensional $\mathrm{k}$ is a $\mathrm{k}$-dimensional subspace of $\mathrm{V}(\mathrm{n}, \mathrm{q})$. The vectors of $\mathrm{C}$ are called codewords. The 
Hamming distance between two code words is defined to be the number of coordinate places in which they differ.the minimum distance of a code is the amallest of the distances between distinct codewords. Such a code is called a [n,k,d]_q-code if its minimum Hamming distance is d. A central problem in coding theory is that of optimizing one of the parameters $\mathrm{n}, \mathrm{k}$ and $\mathrm{d}$ for given values of the other two and q-fixed. One of the variants is(Yahya \& Salim , 2018,pp.2319-746).Codes with parameters $\left[\mathrm{g}_{\mathrm{q}}(\mathrm{k}, \mathrm{d}), \mathrm{k}, \mathrm{d}\right]_{\mathrm{q}}$ are colled Griesmer codes. Thers exists a relationship between $(\mathrm{k}, \mathrm{r})$-arc in $\mathrm{PG}(2, \mathrm{q})$ and $[\mathrm{n}, 3, \mathrm{~d}]_{\mathrm{q}}$ codes , given by the following theorem."

\subsection{Describe Relevant Scholarship}

Theorem (1.3.1)there exists a projective $[n, 3, d]_{q}$ code if and only if there exists an (n, n-d)-arc in PG(2, q). In this paper we consider the case $\mathrm{q}=17$ and the elements of $\mathrm{GF}(17)$ are denoted by $0,1,2,3,4,5,6,7,8$, 9,10,11,12,13,14,15,16 ( Yahya , 2018,pp.24-40)."

\subsection{Geometric Builiding Approach}

It is evident that in $\mathrm{PG}(2, \mathrm{q})$ (q is prime) three lines in general position form a (3q, 2)- blocking set. The problem of finding a 2-blocking set with less than $3 \mathrm{q}$ components had for long remained unsolved until recently Braun et al.Discovered the first example of such a set. They constructed the $(51,2)$ - blocking set in PG(2, 17),consisting of the following points: "

$\{(1,0,0),(0,1,0),(1,0,13),(1,1,13),(1,2,13),(1,3,13),(1,4,0),(1,4,1),(1,2,4),(1,4,3),(1,4,4)$,

$(1,4,5),(1,4,6),(1,4,7),(1,4,8),(1,4,9),(1,4,10),(1,4,11),(1,4,12),(1,4,13),(1,4,14),(0,1,14)$,

$(1,4,15),(1,4,16),(1,5,13),(1,6,13),(1,7,13),(1,8,13),(1,9,13),(1,10,13),(1,11,13),(1,12,13)$,

$(1,13,0),(1,13,1),(1,13,2),(1,13,3),(1,13,4),(1,13,5),(1,13,6),(1,13,7),(1,13,8),(1,13,9)$,

$(1,13,10),(1,13,11),(1,13,12),(1,13,13),(1,13,14),(1,13,15)(1,13,16),(1,14,13),(1,15,3)\}$

The $\{51,2\}$ - blocking set are complement the $(256,16)$-arc in $\mathrm{PG}(2,17)$,Which is geometrically constructed by the researcher method

1) Get new code $[256,3,240]_{17}$

2) Get a new $(256,16)$-arc. as shown in the table 7."

\section{Method(Geometric Building Approach)}

We construction of new $(257,16)$ - arc and new projective $[257,3,241]_{17}$ code and getting:

Theorem( 2.1 .1$)$ :There exists a $(50,2)$ - blocking set in $\mathrm{PG}(2,17)$ and a $(257,16)$ - arc .Consider the accompanying 60 points in $\mathrm{PG}(2,17)$ as shown in the table 1and table 2 and table 3 and table 4 .

Table $1 . \mathrm{L}_{1}$

\begin{tabular}{|c|c|c|c|c|c|c|c|c|}
\hline $\begin{array}{c}I \\
\mathrm{Mi}\end{array}$ & $\begin{array}{c}1 \\
(1,0,0)\end{array}$ & $\begin{array}{c}2 \\
(0,1,0)\end{array}$ & $\begin{array}{c}3 \\
(1,5,0)\end{array}$ & \multicolumn{2}{|c|}{$\begin{array}{c}4 \\
(1,13,0)\end{array}$} & $\begin{array}{c}5 \\
(1,6,0)\end{array}$ & $\begin{array}{c}6 \\
(1,9,0)\end{array}$ & $\begin{array}{c}7 \\
(1,14,0)\end{array}$ \\
\hline I & 8 & 9 & 10 & \multicolumn{2}{|c|}{11} & 12 & 13 & 14 \\
\hline Mi & $(1,8,0)$ & $(1,7,0)$ & $(1,15,0)$ & \multicolumn{2}{|c|}{$(1,3,0)$} & $(1,16,0)$ & $(1,11,0)$ & $(1,10,0)$ \\
\hline I & 15 & 16 & 17 & \multicolumn{2}{|c|}{18} & & & \\
\hline Mi & $(1,4,0)$ & $(1,12,0)$ & $(1,1,0)$ & \multicolumn{2}{|c|}{$(1,2,0)$} & & & \\
\hline \multicolumn{9}{|c|}{ Table 2. $\mathrm{L}_{2}$} \\
\hline$I$ & 1 & 2 & 3 & 4 & 5 & 6 & 7 & 8 \\
\hline $\mathrm{Ni}$ & $(0,1,0)$ & $(0,0,1)$ & $(0,1,5)$ & $(0,1,13)$ & $(0,1,6)$ & $(0,1,9)$ & $(0,1,14)$ & $(0,1,8)$ \\
\hline$I$ & 9 & 10 & 11 & 12 & 13 & 14 & 15 & 16 \\
\hline $\mathrm{Ni}$ & $(0,1,7)$ & $(0,1,15)$ & $(0,1,3)$ & $(0,1,16)$ & $(0,1,11)$ & $(0,1,10)$ & $(0,1,4)$ & $(0,1,12)$ \\
\hline$I$ & 17 & 18 & & & & & & \\
\hline $\mathrm{Ni}$ & $(0,1,1)$ & $(0,1,2)$ & & & & & & \\
\hline
\end{tabular}


Table 3. $\mathrm{L}_{5}$

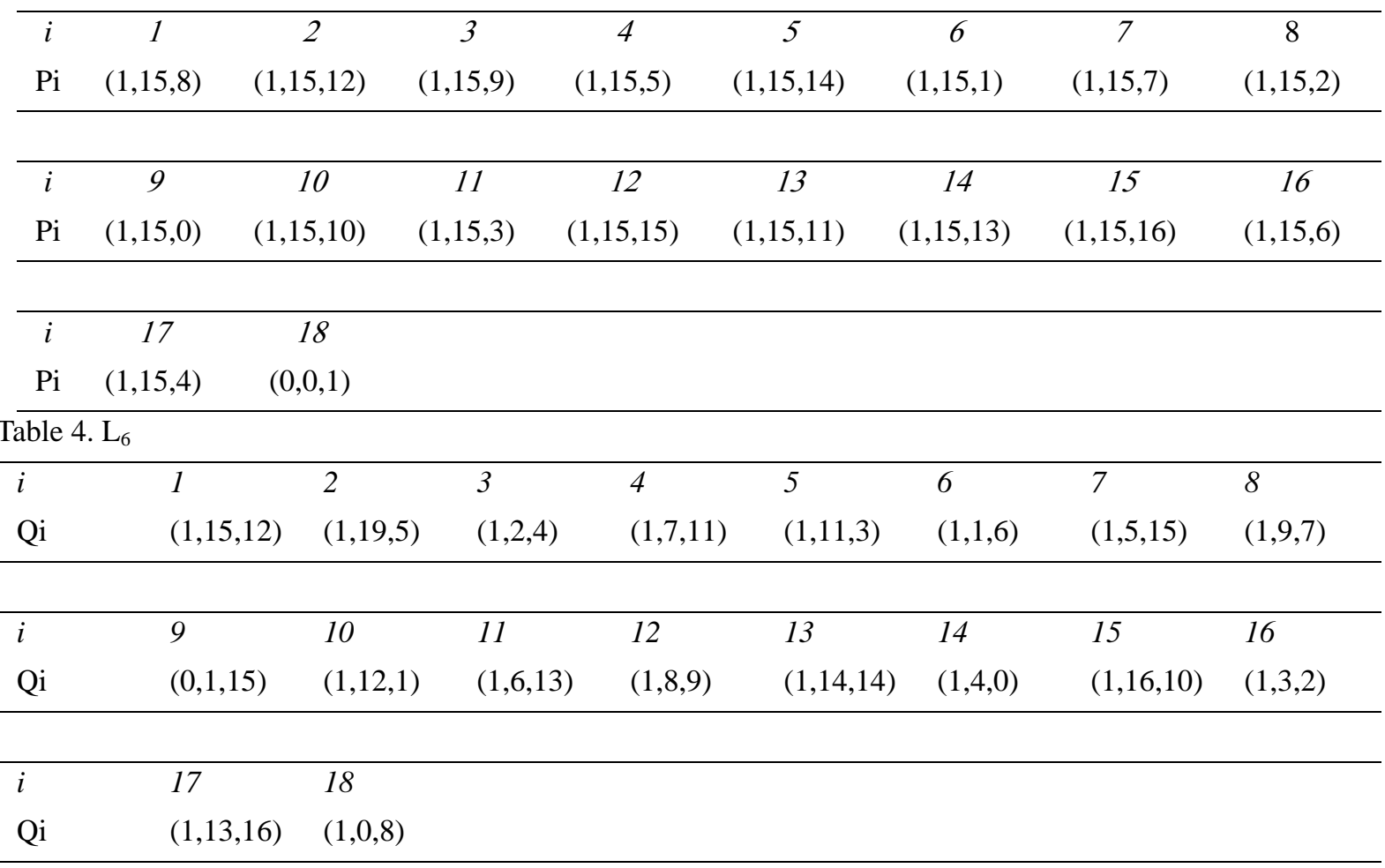

The lines $\mathrm{Li}: \mathrm{a}_{\mathrm{i}} \mathrm{x}+\mathrm{b}_{\mathrm{i}} \mathrm{y}+\mathrm{c}_{\mathrm{i}} \mathrm{z}=0,(\mathrm{i}=1,2,5,6)$ are chosen with the goal that each lineLi contains the point (ai, bi, ci ),.The point $\mathrm{Mi}(\mathrm{I}=1,2, \ldots, 18)$ have a place with the line $\mathrm{L}_{1}: \mathrm{Z}=0$, The points $\mathrm{Ni}(\mathrm{I}=1,2, \ldots, 18)$ have a place with the line $\mathrm{L}_{2}: \mathrm{X}=0$. The points $\mathrm{Pi}(\mathrm{I}=1,2, \ldots, 18)$ lie on hold $\mathrm{L}_{5}: 9 \mathrm{X}+13 \mathrm{Y}=0$, and the points $\mathrm{Qi}(\mathrm{I}=1$, $2, \ldots, 18)$ are the purposes of the line $\mathrm{L}_{6}: 14 \mathrm{X}+5 \mathrm{Y}+11 \mathrm{Z}=0$. The four lines meet pairwise at the points $\mathrm{M}_{1}=\mathrm{Q}_{1}$, $\mathrm{M}_{2}=\mathrm{P}_{2}, \mathrm{~N}_{1}=\mathrm{P}_{1}, \mathrm{~N}_{2}=\mathrm{Q}_{2}, \mathrm{M}_{6}=\mathrm{N}_{6}, \mathrm{P}_{11}=\mathrm{Q}_{11}$ and $\mathrm{P} 11=\mathrm{Q} 11$, i.e. they are lines in general position in $\mathrm{PG}(2,17)$ the 18 lines which pass through the points $(0,0,1)$ have equations :

$$
\begin{aligned}
& P 1: Y=0 \\
& P 2: X=0 \\
& p 3: x+y=0 \\
& p 5: x+3 y=0 \\
& p 7: x+5 y=0 \\
& \therefore \quad p 4: x+2 y=0 \\
& p 9: y+7 y=0 \\
& p 11: x+9 y=0 \\
& \text { p6: } x+4 y=0 \\
& p 8: x+6 y=0 \\
& p 13: x+11 y=0 \\
& \begin{aligned}
\therefore & p 10: x+8 y=0 \\
& p 12: x+10 y=0
\end{aligned} \\
& p 15: x+13 y=0 \\
& p 17: y+15 y=0 \\
& p 14: x+12 y=0 \\
& p 16: x+14 y=0 \\
& p 19: x+17 y=0 \\
& p 18: x+16 y=0 \\
& \text { p20: } x+18 y=0
\end{aligned}
$$

The careful analysis of the lines $\mathrm{L}_{1}, \mathrm{~L}_{2}, \mathrm{~L}_{5}, \mathrm{~L}_{6}$ shows that each quadruple (in the case of $\mathrm{i}=6,11$ - each triple, and in the case of $\mathrm{i}=1,2$ - each pair) of points $\mathrm{Mi}, \mathrm{Ni}, \mathrm{Pi}, \mathrm{Qi}(\mathrm{i}=1,2 \ldots, 18)$ has a place with one of the18 lines pi. Presently given us a chance to set the accompanying undertaking: Remove20 points from the set L1 $\cup$ L2 $\cup$ L5 $\cup$ L6, so that:

a) There is no line in $\operatorname{PG}(2,17)$ which is unique in relation to li and which contains four of the expelled points

b) The lines that contain three of the evacuated points meet at most four new points A1, A2, A3,A4

C) The new four points added at least two points are deleted

d) The lines that contain only two of the evacuated points don't go through the crossing points M1,M2, N1, N2,M6 and P11. 
The conditions (a)- (d) will ensure that including the points A1, A2, A3, A4 to the arrangement of outstanding purposes of the lines, we will acquire a 2-blocking set without any than 50. Clearly we ought not expel any points from the quadruples $\mathrm{Mi}, \mathrm{Ni}, \mathrm{Pi}, \mathrm{Qi}, \mathrm{I}=1,2$; generally, the lines $\mathrm{p} 2: \mathrm{x}=0$ and $\mathrm{p} 1: \mathrm{y}=0$ will move toward becoming 1-or 0-secants. Correspondingly, it isn't alluring to expel any points from thequadruples Mi , $\mathrm{Ni}, \mathrm{Pi}, \mathrm{Qi}, \mathrm{I}=6,11$, on the grounds that expelling a crossing point .

Now we select four lines intersecting six points and lines are $\mathrm{L}_{1}, \mathrm{~L}_{2}, \mathrm{~L}_{5}, \mathrm{~L}_{6}$ such that

$|\mathrm{L} 1 \cap \mathrm{L} 2|=(0,1,0)$

$|\mathrm{L} 5 \cap \mathrm{L} 6|=(1,15,12)$

$|\mathrm{L} 1 \cap \mathrm{L} 5|=(1,15,0)$

$|\mathrm{L} 1 \cap \mathrm{L} 6|=(1,4,0)$

$|\mathrm{L} 2 \cap \mathrm{L} 5|=(0,0,1)$

$|\mathrm{L} 2 \cap \mathrm{L} 6|=(0,1,15)$

So the six common points are the sequence points $[18,356,284,290,357,24]$

Now we draw the intersection points and show the intersection as shown in figure 1."

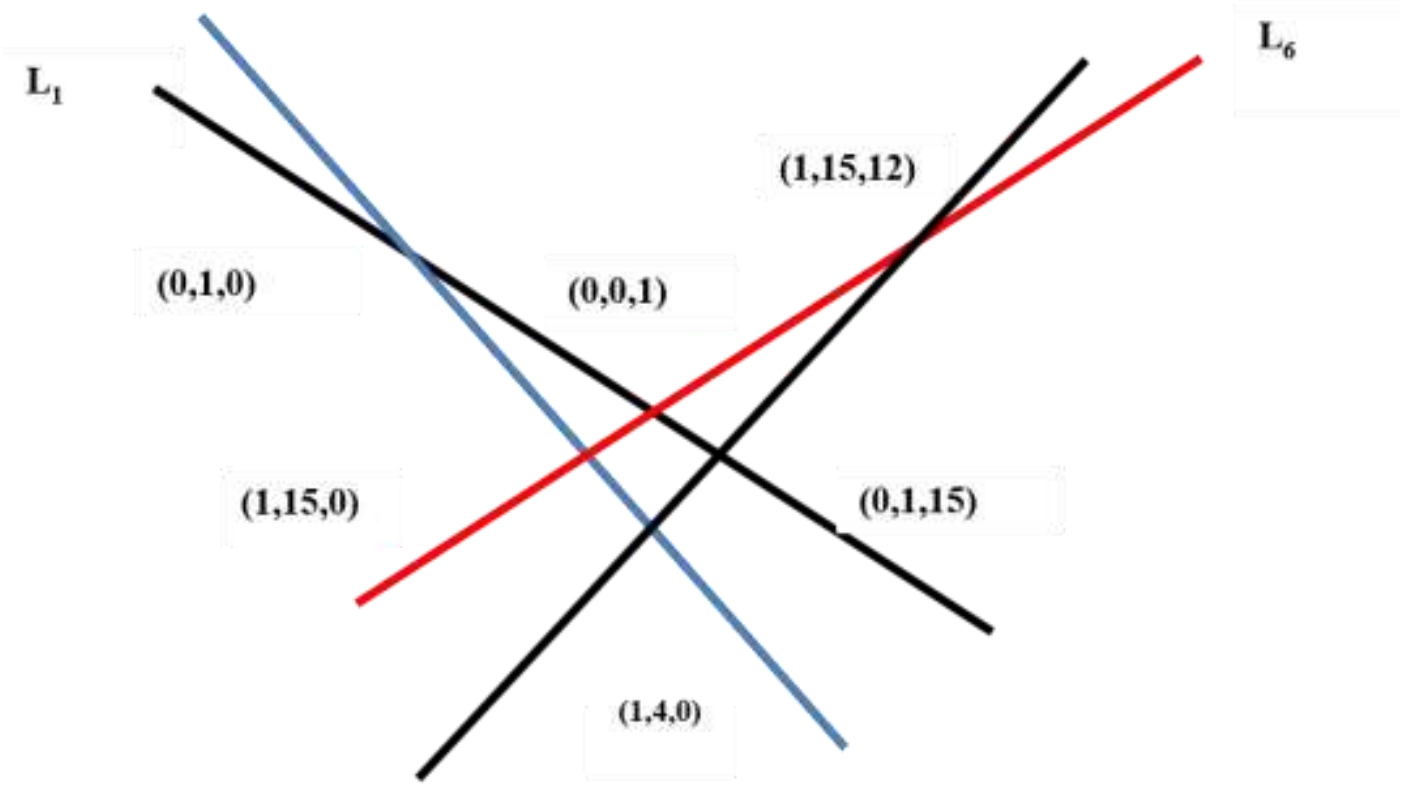

Figure 1.

The set of removed points

$A=\{(1,14,0),(1,7,0),(1,16,0),(1,1,0),(1,2,0),(0,1,6),(0,1,3),(0,1,11),(0,1,1)$,

$(0,1,2),(1,15,9),(1,15,14),(1,15,7),(1,15,13),(1,15,4),(1,10,5),(1,11,3),(1,5,15),(1,13,16),(1,0,8)\}$

is a $(20,4)$-arc in $\mathrm{PG}(2,17)$.

The 3-secants of An, i.e. the lines not the same as li, with the end goal that each contains three of the evacuated points, are

$\begin{array}{ll}\mathrm{g}_{1}=\mathrm{x}+14 \mathrm{y}=0 & \mathrm{M}_{5}, \mathrm{~N}_{2}, \mathrm{Q}_{11} \in \mathrm{g} 1 \\ \mathrm{~g}_{2}=\mathrm{x}+7 \mathrm{y}=0 & \mathrm{M}_{16}, \mathrm{P}_{18}, \mathrm{Q}_{10} \in \mathrm{g} 2 \\ \mathrm{~g}_{3}=\mathrm{x}+16 \mathrm{y}=0 & \mathrm{M}_{17}, \mathrm{P}_{18}, \mathrm{Q}_{6} \in \mathrm{g} 3 \\ \mathrm{~g}_{4}=\mathrm{x}+\mathrm{y}=0 & \mathrm{M}_{12}, \mathrm{~N}_{2}, \mathrm{Q}_{15} \in \mathrm{g} 4 \\ \mathrm{~g}_{5}=\mathrm{x}+2 \mathrm{y}=0 & \mathrm{M}_{8}, \mathrm{P}_{18}, \mathrm{Q}_{12} \in \mathrm{g} 5 \\ \mathrm{~g}_{6}=\mathrm{y}+6 \mathrm{z}=0 & \mathrm{~N}_{7}, \mathrm{P}_{16}, \mathrm{Q}_{8} \in \mathrm{g} 6 \\ \mathrm{~g}_{7}=\mathrm{y}+3 \mathrm{z}=0 & \mathrm{M}_{1}, \mathrm{~N}_{13}, \mathrm{Q}_{1} \in \mathrm{g} 7 \\ \mathrm{~g}_{8}=\mathrm{y}+11 \mathrm{z}=0 & \mathrm{P}_{13}, \mathrm{~N}_{11}, \mathrm{Q}_{7} \in \mathrm{g} 8 \\ \mathrm{~g}_{9}=\mathrm{y}+\mathrm{z}=0 & \mathrm{~N}_{12}, \mathrm{P}_{8}, \mathrm{Q}_{12} \in \mathrm{g} 9\end{array}$




$$
\begin{array}{ll}
\mathrm{g}_{10}=\mathrm{y}+2 \mathrm{z}=0 & \mathrm{~N}_{8}, \mathrm{P}_{6}, \mathrm{Q}_{5} \in \mathrm{g} 10 \\
\mathrm{~g}_{11}=\mathrm{x}+15 \mathrm{y}+9 \mathrm{z}=0 & \mathrm{M}_{6}, \mathrm{~N}_{15}, \mathrm{P}_{7} \in \mathrm{g} 11 \\
\mathrm{~g}_{12}=\mathrm{x}+15 \mathrm{y}+14 \mathrm{z}=0 & \mathrm{~N}_{3}, \mathrm{P}_{14}, \mathrm{Q}_{2} \in \mathrm{g} 12 \\
\mathrm{~g}_{13}=\mathrm{x}+15 \mathrm{y}+7 \mathrm{z}=0 & \mathrm{~N}_{14}, \mathrm{P}_{3}, \mathrm{Q}_{5} \in \mathrm{g} 13 \\
\mathrm{~g}_{14}=\mathrm{x}+15 \mathrm{y}+13 \mathrm{z}=0 & \mathrm{M}_{6}, \mathrm{~N}_{8}, \mathrm{P}_{5} \in \mathrm{g} 14 \\
\mathrm{~g}_{15}=\mathrm{x}+15 \mathrm{y}+4 \mathrm{z}=0 & \mathrm{M}_{6}, \mathrm{P}_{11}, \mathrm{Q}_{7} \in \mathrm{g} 15 \\
\mathrm{~g}_{15}=\mathrm{x}+10 \mathrm{y}+5 \mathrm{z}=0 & \mathrm{M}_{3}, \mathrm{~N}_{10}, \mathrm{P}_{5} \in \mathrm{g} 16 \\
\mathrm{~g}_{17}=\mathrm{x}+11 \mathrm{y}+3 \mathrm{z}=0 & \mathrm{M}_{11}, \mathrm{~N}_{18}, \mathrm{Q}_{10} \in \mathrm{g} 17 \\
\mathrm{~g}_{18}=\mathrm{x}+5 \mathrm{y}+15 \mathrm{z}=0 & \mathrm{M}_{14}, \mathrm{P}_{17}, \mathrm{Q}_{17} \in \mathrm{g} 18 \\
\mathrm{~g}_{19}=\mathrm{x}+13 \mathrm{y}+16 \mathrm{z}=0 & \mathrm{M}_{4}, \mathrm{~N}_{4}, \mathrm{P}_{3} \in \mathrm{g} 19 \\
\mathrm{~g}_{20}=\mathrm{x}+8 \mathrm{z}=0 & \mathrm{M}_{2}, \mathrm{P}_{8}, \mathrm{Q}_{16} \in \mathrm{g} 20
\end{array}
$$

Each line $g i$ intersects some line $\boldsymbol{l} \boldsymbol{i}$ at a point not in the set A. Indeed:

$$
\begin{array}{lll}
\mathrm{g}_{1} \cap \mathrm{L}_{1}=(1,1,0) & \mathrm{g}_{2} \cap \mathrm{L}_{5}=(1,15,13) & \mathrm{g}_{3} \cap \mathrm{L}_{2}=(0,1,3) \\
\mathrm{g}_{4} \cap \mathrm{L}_{1}=(1,3,0) & \mathrm{g}_{5} \cap \mathrm{L}_{5}=(0,1,13) & \mathrm{g}_{6} \mathrm{~L}_{6}=(1,10,5) \\
\mathrm{g}_{7} \cap \mathrm{L}_{1}=(1,14,0) & \mathrm{g}_{8} \cap \mathrm{L}_{2}=(0,1,5) & \mathrm{g}_{6} \mathrm{~L}_{2}=(0,1,2) \\
\mathrm{g}_{10} \cap \mathrm{L}_{6}=(1,0,8) & \mathrm{g}_{11} \cap \mathrm{L}_{2}=(0,1,9) & \mathrm{g}_{12} \cap \mathrm{L}_{5}=(1,15,8) \\
\mathrm{g}_{13} \cap \mathrm{L}_{6}=(1,5,15) & \mathrm{g}_{14} \cap \mathrm{L}_{1}=(1,16,0) & \mathrm{g}_{15} \mathrm{LL}_{2}=(0,1,6) \\
\mathrm{g}_{16} \mathrm{LL}_{5}=(1,15,3) & \mathrm{g}_{17} \cap \mathrm{L}_{6}=(1,3,2) & \mathrm{g}_{18} \cap \mathrm{L}_{1}=(1,8,0) \\
\mathrm{g}_{19} \cap \mathrm{L}_{2}=(0,1,11) & \mathrm{g}_{20} \cap \mathrm{L}_{5}(1,15,11) &
\end{array}
$$

Furthermore, the lines $g i$ intersect one another in quadruples at the points. $(1,11,3),(0,1,1),(1,15,4),(1,13,16)$

More precisely

$$
\begin{gathered}
g 1 \cap g 3 \cap g 7 \cap g 19 \cap g 20=(1,13,16) \\
g 2 \cap g 7 \cap g 12 \cap g 17 \cap g 18=(0,1,1) \\
g 4 \cap g 5 \cap g 9 \cap g 15 \cap g 18=(1,11,3) \\
g 5 \cap g 6 \cap g 10 \cap g 13 \cap g 12=(1,15,4)
\end{gathered}
$$

Therefore the points are $(1,11,3),(0,1,1),(1,15,4),(1,13,16) \mathrm{A} 1, \mathrm{~A} 2, \mathrm{~A} 3, \mathrm{~A} 4$.

Adding these four points to the rest 50 points, we obtain the set

$$
B=\left\{\begin{array}{r}
(1,0,0),(0,1,0),(1,5,0),(1,13,0),(1,6,0),(1,9,0),(1,8,0),(1,15,0),(1,3,0),(1,11,0), \\
(1,10,0),(1,4,0),(1,12,0),(0,0,1),(0,1,5),(0,1,13),(0,1,9),(0,1,14),(0,1,8),(0,1,7),(0,1,15) \\
(0,1,16),(0,1,10),(0,1,4),(0,1,12),(1,15,8),(1,15,12),(1,15,5),(1,15,1),(1,15,2),(1,15,10), \\
(1,15,3),(1,15,15),(1,15,11),(1,15,16),(1,15,6),(1,2,4),(1,7,11),(1,1,6),(1,9,7),(1,12,1), \\
(1,6,13),(1,8,9),(1,14,14),(1,16,10),(1,3,2),(1,11,3),(0,1,1),(1,15,4),(1,3,16)
\end{array}\right\}
$$

Thus, we obtained the $(50,2)$-blocking set at the PG $(2,17)$., we apply (1.2.4) agencies:

$$
\begin{aligned}
& |50| \geq(5(17)+7) / 2 \\
& |50| \geq 46 \text {, Thus we got the arc }-(257.16) \text { and its points are: } M_{16}(2,17)=
\end{aligned}
$$




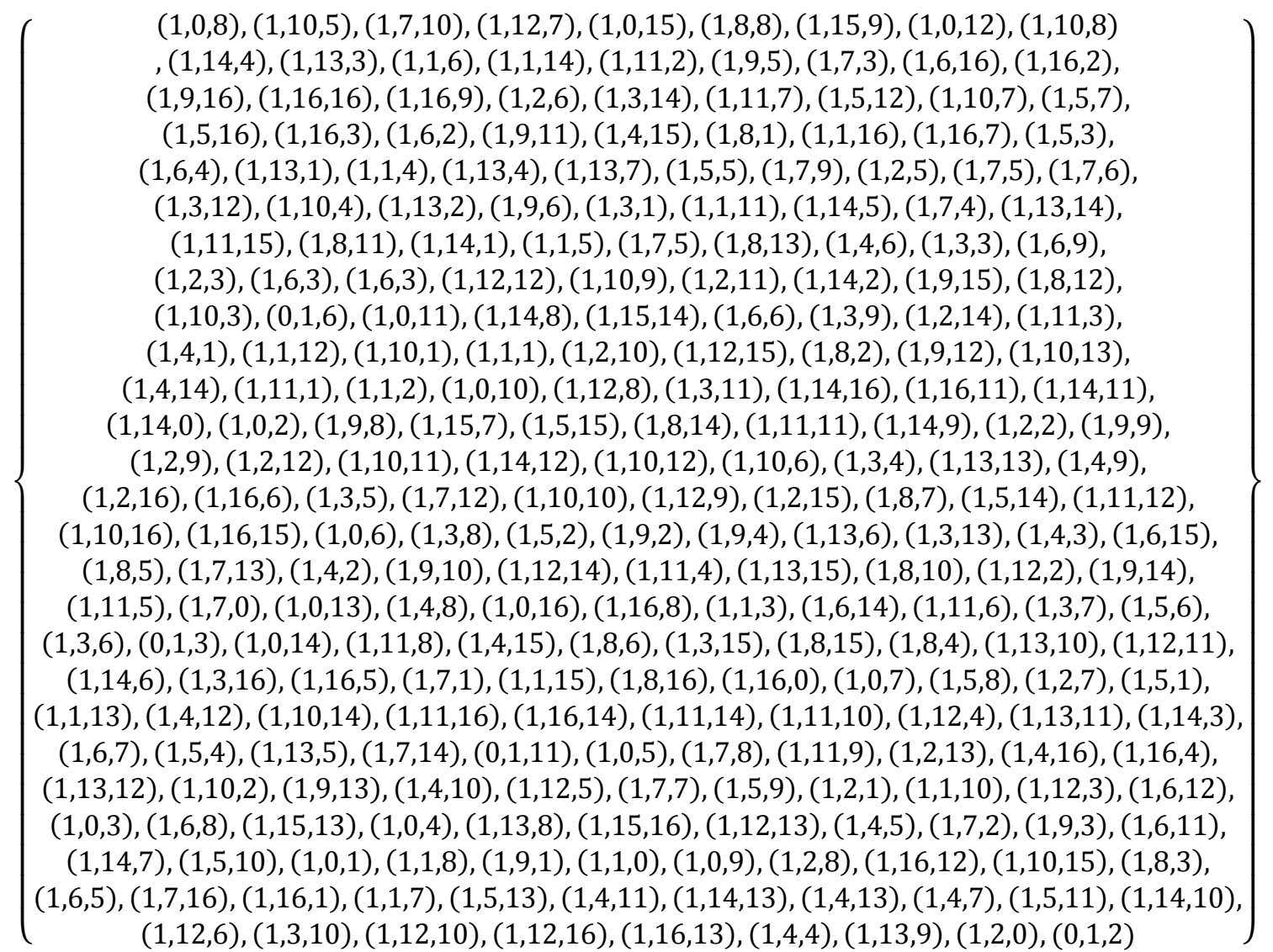

According to the theorem (1.3.1) there is a linear code [257,3,241] ${ }_{17}$.

To make sure that the new arc - $(257,16)$ is complete "we apply the theorem(1.2.5):

$(\mathrm{q}+1-\mathrm{r}) \mathrm{T}_{\mathrm{r}} \geq \mathrm{q}^{2}+\mathrm{q}+1-\mathrm{k},(17+1-16) \mathrm{T}_{16} \geq \frac{50}{2}, \mathrm{~T}_{16} \geq 25,99 \geq 25$, Thus the $(257,16)$-arc is complete.

Which is required as shown in Table 5, Table 6, Table 7.""

Table 5. Projection Level Points in PG(2,17)

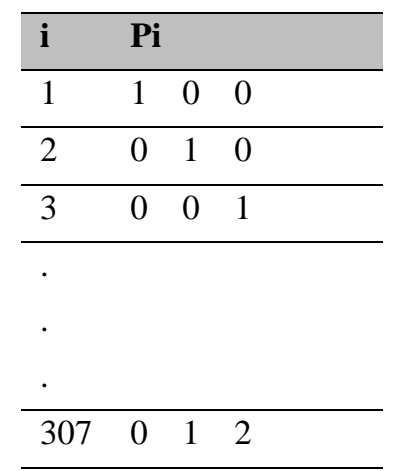


Table 6. Projection Level Lines in PG $(2,17)$

\begin{tabular}{lllllllllllllllllll}
\hline $\mathrm{L}_{1}$ & 1 & 2 & 10 & 16 & 87 & 110 & 120 & 152 & 176 & 180 & 192 & 211 & 233 & 254 & 259 & 272 & 279 & 306 \\
\hline $\mathrm{L}_{2}$ & 2 & 3 & 11 & 17 & 88 & 111 & 121 & 153 & 177 & 181 & 193 & 212 & 234 & 255 & 260 & 273 & 280 & 307 \\
\hline $\mathrm{L}_{3}$ & 3 & 4 & 12 & 18 & 89 & 112 & 122 & 154 & 178 & 182 & 194 & 213 & 235 & 256 & 261 & 274 & 281 & 1 \\
\hline
\end{tabular}

Table 7. The bound of linear codes (Ball,2018)

\begin{tabular}{|c|c|c|c|c|c|}
\hline $\mathrm{q}$ & 11 & 13 & 16 & 17 & 19 \\
\hline 2 & 12 & 14 & 18 & 18 & 20 \\
\hline 3 & 21 & 23 & 28 & $28-33$ & $31-39$ \\
\hline 4 & 32 & $38-40$ & 52 & $48-52$ & $52-58$ \\
\hline 5 & $43-45$ & $49-53$ & 65 & $61-69$ & $68-77$ \\
\hline 6 & 56 & $64-66$ & $78-82$ & $79-86$ & $86-96$ \\
\hline 7 & 67 & 79 & $93-97$ & $95-103$ & $105-115$ \\
\hline 8 & 78 & 92 & 120 & $114-120$ & $126-134$ \\
\hline 9 & $89-90$ & 105 & $129-131$ & 137 & $147-153$ \\
\hline 10 & $100-102$ & $118-119$ & $142-148$ & 154 & 172 \\
\hline 11 & & $132-133$ & $159-164$ & $166-171$ & 191 \\
\hline 12 & & $143-147$ & $180-181$ & $183-189$ & 204-210 \\
\hline 13 & & & 195-199 & 205-207 & $225-230$ \\
\hline 14 & & & $210-214$ & $221-225$ & $243-250$ \\
\hline 15 & & & 231 & $239-243$ & $265-270$ \\
\hline 16 & & & & $256-261$ & $286-290$ \\
\hline 17 & & & & & $305-310$ \\
\hline 18 & & & & & $324-330$ \\
\hline
\end{tabular}

3. Conclusion: Of the results we obtained

1) At the projective plane PG $(2,17)$.

a) There existent new $(256,16)$ - arc and new $(51,2)$ - Blocking sets

b) There existent new $(257,16)$ - arc and new $(50,2)$ - Blocking sets

2) Improvement of linear codes in the projection plane PG $(2,17)$ Theorem $(2.1 .1)$

improvement Linear code $[256,3,240] 17$ to $[257,3,240] 17$

\section{References}

Ball, S. (2018). Three-dimensional Linear Codes. On line table, http://mat-web.upc.edu/people/simeon,Michael.ball/codebounds.html.

Braun, M. (2018). New Lower bounds on the size of arcs and new Optional Projective Linear Codes. The Faculty of Computer Science of The University of Applied Sciences, DarmsTadt, Germany, for this Publication. Cite as: http:// arXiv:1808.02702 [math.CO]

Hirschfeld, J.W.P. (1979). Projective Geometries over finite fields. Oxford Clarendon Press; New York: Oxford University Press. Bib ID: 1036729, ISBN-13: 978-0198502951, ISBN-ID10: 0198502958" 
Kasm, N.Y. \& Ibrahim, H.Sh. (2019). The optimal size of $\{b, t\}$-blocking set When $t=3,4$ By intersection the tangents in PG (2, q). Modern Applied Science, 13(7). ISSN: 1913-1844, E-ISSN: 1913-1852. Published by Canadian Center of Science and Education. URL: https://doi.org/10.5539/mas.v13n7p

Kasm, N.Y. \& Hamad, A.Z. (2019). Applications of Algebraic Geometry in Cryptography. Modern Applied Science, 13(5). ISSN: 1913-1844, E-ISSN: 1913-1852. Published by Canadian Center of Science and Education. URL: https://doi.org/10.5539/mas.v13n5p130

Nilsson, A., Johansson, T., \& Wagner, P.S. (2019). Error Amplification in Cod-based Cryptography. IACR Transactions on Cryptographic Hardware and Embedded Systems, 238-258. https://doi.org/10.13154/tches.V2019.i1.238-258.

Yahya, N.Y.K. (2018). A geometric Construction of Complete (k, r)-arc in PG $(2,7)$ and the Related Projective [n, 3, d $]_{7}$ Codes. AL-Rafidain Journal of Computer Sciences and Mathematics, 12(1), 24-40, University of Mosul, Mosul-Iraq. ISSN: 18154816, https://doi.org/10.13140/RG.2.2.16543.25767.

Yahya, N.Y.K. (2014). A Non PGL (3, q) k-arcs in the projective plane of order 37. Tikrit Journal of Pure Science, 19(1), 135-145. ISSN: 1813-1662, Tikrit University, Tikrit-Iraq, https://doi.org/ 10.13140/RG.2.2.23254.14401

Yahya, N.Y.K. (2012). Existence of Minimal Blocking Sets of Size 31 in the Projective Plane PG (2, 17). Journal of University of Babylon/Pure and Applied Sciences, 20(4), 1138-1146, ISSN: 19920652, 23128135, Babylon University, Babul-Iraq, https://doi.org/ 10.13140/RG.2.2.10146.94407

Yahya, N.Y.K. (2014). The Use of 7- Blocking Sets in Galois Geometries. Journal of University of Babylon/Pure and Applied Sciences, 22(4), 1229-1235. ISSN: 19920652, 23128135, Babylon University, Babul-Iraq, https://doi.org/10.13140/RG.2.2.16857.83044

Yahya, N.Y.K. \& Salim, M.N. (2018). The Geometric Approach to Existences Linear $[n, k, d]_{13}$ Code, International Journal of Enhanced Research in science, Technology and Engineering, ISSN: 2319-7463. https:// doi.org/ 10.13140/RG.2.2.16018.96960

Yahya, N.Y.K. \& Salim, M.N. (2019). New Geometric Methods for prove Existence three- Dimensional linear $[97,3,87]_{11}$ and $[143,3,131]_{13}$ codes, Journal of education and science, 28(1812-125X), 312-333. University of Mosul, Mosul-Iraq. https//:doi.org/ 10.13140/RG.2.2.29944.08965

Yahya, N.Y.K. \& Salim, M.N. (2019). 17 New Existences linear [n, 3, d $]_{19}$ Codes by Geometric Structure Method in PG (2, 19), AL-Rafidain Journal of Computer Sciences and Mathematics, 13(1), ISSN 1815-4816, 61-86, University of Mosul, Mosul-Iraq. https://doi.org /10.13140/RG.2.2.18697.29284.

Yahya, N.Y.K. \& Hamad. A.Z. (2019). A geometric Construction of a $(56,2)$-blocking set in PG $(2,19)$ and on three dimensional Linear $[325,3,307]_{19}$ Griesmer Code. AL-Rafidain Journal of Computer Sciences and Mathematics, University of Mosul, Mosul-Iraq. Accepted for publication, In press. https://doi.org/10.13140/RG.2.2.28763.62246

\section{Copyrights}

Copyright for this article is retained by the author(s), with first publication rights granted to the journal.

This is an open-access article distributed under the terms and conditions of the Creative Commons Attribution license (http://creativecommons.org/licenses/by/4.0/). 